\title{
Bupropion improved symptoms in adults with attention deficit hyperactivity disorder
}

Wilens TE, Spencer TJ, Biederman J, et al. A controlled clinical trial of bupropion for attention deficit hyperactivity

disorder in adults. Am J Psychiatry $2001 \mathrm{Feb} ; 158: 282-8$.

QUESTION: In adults with attention deficit hyperactivity disorder (ADHD), is bupropion more effective than placebo?

Design

6 week randomised (allocation concealed*), blinded \{clinicians, patients, and outcome assessors $\} \dagger^{*}$, placebo controlled trial.

\section{Setting}

Psychopharmacology clinic of the Massachusetts General Hospital, Boston, Massachusetts, USA.

\section{Patients}

40 patients who were $20-59$ years of age (mean age 38 y, $55 \%$ men) and had ADHD according to DSM-IV criteria. Exclusion criteria were clinically significant chronic medical conditions, history of cardiac arrhythmias or seizures, intellectual impairment (intelligence quotient $<75$ ), organic brain disorders, clinically unstable psychiatric conditions, bipolar disorder, drug or alcohol abuse within the past 6 months, or current use of psychotropics. 38 patients $(95 \%)$ completed the study.

\section{Intervention}

Patients were allocated to $200 \mathrm{mg}$ /day of bupropion $(n=21)$ or placebo $(n=19)$. The dose was titrated up to $200 \mathrm{mg}$ twice daily by week 4 .

\section{Main outcome measures}

ADHD, depression, and anxiety symptoms were measured using the Clinical Global Impression (CGI) scale, the ADHD Rating Scale, the Hamilton Depression Rating Scale (HDRS), the Beck Depression Inventory (BDI), and the Hamilton Anxiety Rating Scale (HARS). Adverse events were also assessed.

\section{Main results}

More patients who received bupropion showed improvement than those who received placebo (score of 1 or 2 [much or very much improved] on the CGI scale, $\mathrm{p}=0.007$; and $\geqslant 30 \%$ reduction in scores on the DSM-IV ADHD symptom checklist, $\mathrm{p}=0.02$ ) (table). More ADHD symptoms improved in the bupropion group patients than in placebo group patients $(100 \% v 44 \%$ of symptoms, $\mathrm{p}<0.001)$. The groups did not differ for scores on the HDRS, the BDI, or the HARS. The groups did not differ for adverse events (table); no serious adverse drug events occurred.

Sources of funding: Glaxo Wellcome Incorporated; National Institutes of Health National Institute on Drug Abuse.

For correspondence: Dr TE Wilens,

Pediatric

Psychopharmacology Clinic, ACC 725, Massachusetts General Hospital, Boston, $M A$ 02114, USA.Fax +1 6177241540.

\section{Conclusion}

In adults with attention deficit hyperactivity disorder, bupropion was more effective than placebo in improving symptoms and did not produce severe adverse effects.
*See glossary.

†Information provided by author.

\section{COMMENTARY}

The study by Wilens et al shows that bupropion may be a valuable option for the treatment of ADHD. For patients who pose reservations or clear contraindications to the use of stimulants, such as comorbid substance abuse, depression, or anxiety disorders, the availability of bupropion could be an important breakthrough in their management. ${ }^{1}$ Bupropion should be easier to comply with than stimulants (once/ day dosage and modified release forms), although a better understanding of the side effect profile might add to this case. Unfortunately, in this study, those groups were excluded and therefore the efficacy of bupropion in those patients remains open to debate and further investigation.

The method of recruitment of participants introduces a degree of selection that could also impinge upon the study's generalisability, because most of the patients were either volunteers or referrals to a specialist service and were from relatively high socioeconomic strata. The number of potential patients was dramatically reduced after the population screening $(74 \%)$, which was probably because of comorbidity. Although no severe adverse effects were reported in the study, 5 patients $(25 \%)$ from the bupropion group needed a dose reduction because of adverse events, and $2(10 \%)$ dropped out as non-compliant. Furthermore, $43 \%$ of those who responded to bupropion decided not to continue with the treatment once the study had ended, which may be relevant to the patient's degree of satisfaction with the drug.

It is becoming clear that bupropion may have its own niche within the therapeutic options for ADHD, but insufficient evidence currently exists to advocate its widespread use conclusively. More trials are needed to ratify the therapeutic validity of bupropion as an alternative treatment to the stimulants, not only in adults but also in younger patients. Future trials should include patients with comorbid substance misuse, depression, or anxiety disorders, where an alternative treatment to the stimulants could be of real benefit. ${ }^{2}$

J C Ferre, LMS, MRCPsych David Nutt, DM, MRCPsych, FRCP University of Bristol Bristol, $U K$

1 Garland EJ. Pharmacotherapy of adolescent attention deficit hyperactivity disorder: challenges, choices and caveats. J Psyhyperactivity disorder: challenges,
chopharmacol 1998;12:385-95.

2 Toone B, Clark M, Young S. Attention-deficit hyperactivity disorder in adults. Advances in Psychiatric Treatment 1999 $5: 112-9$.

Bupropion v placebo for adults with attention deficit hyperactivity disorder (ADHD) at 6 weeks:

\begin{tabular}{lllll}
\hline Outcomes & Bupropion & Placebo & RBI (95\% Cl) & NNT (CI) \\
Much or very much improved on CGI scale & $52 \%$ & $11 \%$ & $398 \%$ (50 to 1767$)$ & 3 (2 to 8$)$ \\
\hline$\geqslant 30 \%$ reduction on DSM-IV ADHD checklist scores & $76 \%$ & $37 \%$ & $107 \%(17$ to 311$)$ & 3 (2 to 12$)$ \\
\hline & & & RRI (Cl) & NNH \\
\hline Any adverse events & $67 \%$ & $58 \%$ & $15 \%(-30$ to 96$)$ & Not significant \\
\hline
\end{tabular}

¥CGI=Clinical Global Impression. Other abbreviations defined in glossary; RBI, RRI, NNT, NNH, and Cl calculated from data in article. 